\title{
UM CASO DE LEGITIMAÇÃO: TEIXEIRA E SOUSA POR MACHADO DE ASSIS (E PAULA BRITO)
}

\section{CRISTIANE NASCIMENTO RODRIGUES}

Universidade Federal de São Carlos

São Carlos, São Paulo, Brasil

Resumo: O presente artigo analisa uma tentativa de legitimação do poeta Antônio Gonçalves Teixeira e Sousa por Machado de Assis e seu editor Francisco de Paula Brito. Através do poema "O gênio adormecido", publicado na Marmota Fluminense em 1855, o então jovem poeta recolocou o nome de Teixeira e Sousa em circulação, dando evidência ao poema épico A Independência do Brasil, publicado em 1847 (Tomo I) e 1855 (Tomo II) por Paula Brito. Machado, assim como outros colaboradores do periódico, provavelmente escrevia de acordo com a mente do editor, compondo versos que, além de consagrar um mestre ou amigo, colocavam novamente seu nome em circulação.

Palavras-chave: Legitimação; circulação; Teixeira e Sousa; Machado de Assis; Paula Brito.

\section{A CASE OF LEGITIMATION:}

\section{TEIXEIRA E SOUSA BY MACHADO DE ASSIS (AND PAULA BRITO)}

Abstract: This article analyzes Machado de Assis and his editor Francisco de Paula Brito's attempts to legitimize the poet Antônio Gonçalves Teixeira e Sousa. By writing the poem, "O gênio adormecido" (The Sleeping Genius), published in Marmota Fluminense in 1855, Machado put the name of Teixeira e Sousa back into circulation and foregrounded the epic poem, A Independência do Brasil (The Independence of Brazil), published in 1847 (Tome I) and 1855 (Tome II) by Paula Brito. Machado, like other collaborators at the newspaper, probably wrote in alignment with the editor, composing verses that, in addition to consecrating a master or friend, put his own name in circulation.

Keywords: Legitimation; Circulation; Teixeira e Sousa; Machado de Assis; Paula Brito. 


\section{Introdução}

[...] a qualquer texto de poesia ou de ficção, perguntar-se-á de onde vem, quem o escreveu, em que data, em que circunstâncias ou a partir de que projeto. O sentido que lhe é dado, o status ou o valor que nele se reconhece, dependem da maneira como se responde a essas questões. (FOUCAULT apud CHARTIER, 2012, p. 40)

$\mathrm{P}$ artindo dessa reflexão de Michel Foucault sobre a importância de conhecer o contexto para dar sentido e até mesmo valor ao texto literário, retomada pelo historiador francês Roger Chartier, realizaremos, primeiramente, uma breve apresentação do poeta Machado de Assis em início de carreira e, em seguida, teceremos uma análise do seu poema "O gênio adormecido", publicado na revista Marmota Fluminense em outubro de 1855. Essa apresentação da presença do então jovem poeta na imprensa literária carioca de meados do século XIX irá considerar sua produção poética e a rede de relações estabelecida em torno da revista e do editor Francisco de Paula Brito. E a análise do poema, em comparação também com trechos de poemas de outros colaboradores da Marmota Fluminense, permitirá colocar em discussão que o à época já conhecido romancista brasileiro, Antônio Gonçalves Teixeira e Sousa, pode ter tido sua imagem de poeta construída nesse poema machadiano a pedido do editor da revista.

Porém, antes de quaisquer apresentações, é necessário aclarar que apesar de o presente artigo conter algumas informações biográficas de Teixeira e Sousa, privilegia-se aqui a análise da construção da "função autor" operada em "O gênio adormecido" por Machado de Assis. De acordo com Chartier (2012, p. 27), inicialmente, a "função autor" foi estabelecida por Foucault como resultado de mecanismos que permitem que alguns textos sejam atribuídos a um nome próprio, ao mesmo tempo que outros não o são. Em outras palavras, essa função permite reconhecer um lugar de enunciação que adquire uma identidade única a partir da seleção e exclusão de certos discursos.

E o poema apresenta uma construção positiva da figura do autor Teixeira e Sousa (funcionando, nesse caso, como "poeta épico"). O jovem poeta, autor das Crisálidas, pode ter tido a iniciativa de homenagear o autor de A Independência do Brasil, assim como é possível que tanto Teixeira e Sousa como seu editor tenham tentado impulsionar a circulação do seu nome e dos seus escritos e, para isso, lançaram mão do trabalho de outros poetas 
colaboradores da Marmota Fluminense, como do ainda adolescente Machado de Assis.

\section{O autor, o editor e o suporte}

Machado de Assis (1839-1908), aos quinze anos, publicou seu primeiro texto literário na imprensa no dia 3 de outubro de 1854. Saído no Periódico dos Pobres e intitulado "Soneto à ilma. sra. D.P.J.A.", o poema homenageava uma senhora casada, cujo nome Petronilha aparece no último verso (ASSIS, 1854, p. 4). Em janeiro do ano seguinte, a Marmota Fluminense, periódico editado por Francisco de Paula Brito, tornou-se o principal veículo de publicação dos textos literários do jovem Machado, principalmente poemas. $\mathrm{O}$ primeiro a estampar as folhas do jornal de variedades foi o poema "Ela" (1855a, p. 3). ${ }^{1} \mathrm{Com}$ epígrafe do português Francisco Gonçalves Braga (1836-1860), poeta atualmente desconhecido, mas figura muito presente no início da carreira literária de Machado, "Ela" enaltece a beleza de um "anjo" ou "donzela" que pode ser uma cantora lírica. ${ }^{2}$ Pouco depois, o poema publicado na sequência, "A palmeira" (1855b, p. 3), foi dedicado a Gonçalves Braga, assim como a quarta publicação na Marmota Fluminense, "Saudades" (1855c, p. 4), que também possui epígrafe do português. Além disso, Braga ainda recebeu do jovem poeta três poemas em sua homenagem: "A saudade" (1855d, p. 3), "No álbum do sr. F.G. Braga" (1855e, p. 3-4) e "Esperança" (1858, p. 2). Nesse sentido, a quantidade de poemas em que se vê o nome de Braga confirma que houve uma troca de experiências literárias entre o português e o brasileiro.

Francisco de Paula Brito (1809-1861), de origem humilde, nasceu e faleceu na cidade do Rio de Janeiro. Foi aprendiz na Tipografia Imperial Nacional (antiga Impressão Régia) e atuou como tipógrafo na oficina de René Ogier e, em seguida, na de Seignot Plancher, o fundador e editor do Jornal do Commercio. Tendo adquirido experiência como compositor, diretor de prensas, redator, tradutor e contista, estabeleceu sua própria tipografia em

\footnotetext{
${ }^{1}$ Seguiram ao poema "Ela", em 1855, os poemas: "A palmeira", "A saudade", "Saudades", "Júlia", "Lembrança de amor", "Teu canto", "A lua", "Meu anjo", "Um sorriso", "Como te amo", "Paródia", "A saudade", "No álbum do sr. F.G. Braga", "A uma menina", "O gênio adormecido", "O Profeta", "O Pão d'açúcar" e "Soneto a S.M. o imperador, o senhor d. Pedro II", totalizando 19 textos nesse ano. Apesar de serem encontrados alguns textos machadianos em outros periódicos a partir de 1856, é no jornal de Paula Brito que se pode ler a maioria. Machado aí publicou até maio de 1861, ano da morte do editor.

${ }^{2}$ Segundo Jean-Michel Massa, nos periódicos brasileiros de meados do século XIX, era comum encontrar poemas de temática amorosa dedicados às atrizes, dançarinas ou cantoras líricas, uma vez que essas figuras públicas despertavam o interesse dos poetas. O biógrafo afirmou que Machado: "Em 1855, dedicou vários poemas a uma bela desconhecida, que não foi possível identificar com segurança. Foram pelo menos seis poemas: 'Ela', 'Lembrança de amor', 'Júlia', 'Meu anjo', 'Teu canto', 'Como te amo' e talvez, 'Um sorriso'". (MASSA, 2009, p. 123)
} 
1831, na Praça da Constituição (antigo Largo do Rossio e atual Praça Tiradentes). Conforme a biógrafa Eunice Ribeiro Gondim "[...] com essa pequena casa comercial, Paula Brito, o idealista, conseguiu ser o iniciador do movimento editorial literário no Brasil" (GONDIM, 1965, p. 14). Em 24 de dezembro de 1861, Machado de Assis publicou uma crônica no jornal Diário do Rio de Janeiro, comentando sobre o falecimento de Paula Brito e, ao mesmo tempo, louvando sua importância para a história da imprensa no país:

Mais um! Este ano há de ser contado como um obituário ilustre, onde todos, o amigo e o cidadão, podem ver inscritos mais de um nome caro ao coração ou ao espírito.

Longa é a lista dos que no espaço desses doze meses, que estão a expirar, têm caído ao abraço tremendo daquela leviana, que não distingue os amantes, como diz o poeta.

Agora é um homem que, pelas suas virtudes sociais e políticas, por sua inteligência e amor ao trabalho, havia conseguido a estima geral.

Começou como impressor, como impressor morreu. Nesta modesta posição tinha em roda de si todas as simpatias.

Paula Brito foi um exemplo raro e bom. Tinha fé nas suas crenças políticas, acreditava sinceramente nos resultados da aplicação delas; tolerante, não fazia injustiça aos seus adversários; sincero, nunca transigiu com eles.

Era também amigo, era sobretudo amigo. Amava a mocidade, porque sabia que ela é a esperança da pátria, e, porque a amava, estendialhe quanto podia a sua proteção.

Em vez de morrer, deixando uma fortuna, que o podia, morreu pobre como vivera, graças ao largo emprego que dava à suas rendas, e ao sentimento generoso que o levava na divisão do que auferia do seu trabalho.

Nestes tempos, de egoísmo e cálculo, deve-se chorar a perda de homens que, como Paula Brito, sobressaem na massa comum dos homens. (ASSIS, 1861, p. 1)

O tipógrafo-editor figura como uma personagem importante porque trabalhou em benefício do progresso das letras no Brasil oitocentista, permitindo que muitos escritores publicassem seus textos.

Seu jornal de maior prestígio foi a Marmota, que circulou entre 1849 e 1864 e contou, entre outros, com os seguintes colaboradores: Joaquim Manuel de Macedo, Teixeira e Sousa, Machado de Assis, Casimiro de Abreu, Laurindo Rabelo, Moreira de Azevedo, Juvenal Galeno. Diferente de outros periódicos de pequena imprensa, a Marmota se manteve firme por mais de dez anos. 
Juliana Siani Simionato comentou que o interesse de Paula Brito em valorizar a literatura produzida no país, principalmente no Rio de Janeiro, através da divulgação de poemas e romances de novos autores, com temas interessantes ao público, pode ter sido uma estratégia de sobrevivência do jornal. Além disso, o empresário e editor frequentemente recebia ajuda financeira do imperador. Assim, pode ter sido proposital seu silêncio em relação à escravidão e aos assuntos políticos, já que a empresa Dois de Dezembro funcionava como por um mecenato (SIMIONATO, 2009, p. 4 e 53). Além da nomeação de sua empresa com a data de aniversário do monarca, a devoção do editor pelo imperador $\mathrm{d}$. Pedro II pode ser vista em várias páginas do periódico. Nos aniversários do monarca, por exemplo, o jornal sempre lhe prestava homenagem. Aliás, o próprio Machado de Assis, em 1855, escreveu o "Soneto a S.M. o imperador, o senhor d. Pedro II" (ASSIS, 1855g, p. 1.), que apareceu estampado na primeira página e que, de acordo com Magalhães Júnior, "pode ter sido por sugestão de Paula Brito" (MAGALHÃES JÚNIOR, 2008, p. 30).

Havia encontros e reuniões literárias nos fundos da loja de Paula Brito para a discussão de assuntos diversos, entre eles política, os fatos da semana, a moda vigente etc., e, obviamente, literatura. Essas reuniões ocorriam graças à Sociedade Petalógica, que recebia esse nome por derivar de "peta" ou "mentira", e que, como observou Magalhães Júnior: "Pretendia satirizar os mentirosos de todos os matizes, inventando mentiras maiores do que as deles, ou contramentiras, como existem muitas, famosas, no folclore de vários países" (MAGALHÃES JÚNIOR, 2008, p. 67). Alguns dos assuntos comentados na Petalógica eram divulgados na Marmota, como, por exemplo, o que explicou o porquê de o grupo receber esse nome:

A Sociedade Petalógica, ou de Petalogia, sociedade que, segundo o seu título, não trata senão de petas, é um ajuntamento de pessoas, mais ou menos instruídas, que há cerca de 20 anos se reúnem num dos lugares mais belos e mais conhecidos dessa Corte. Criada espontaneamente sem nome, ao princípio o seu fim era todo político; mas como mudam-se os tempos e nós mudamos com eles - tempora mutantur, nos et mutamur in illis -, passou a ser unicamente recreativa, podendo todo o mundo que nela tem assento expender com franqueza a sua opinião, contanto que haja de responder pelos abusos que cometer no exercício desse direito. Exceto vida particular de famílias, de tudo se trata na Sociedade Petalógica! (MARMOTA FLUMINENSE, RJ, n. 380, 5 jul. 1853, p. 1) 
Machado de Assis e seu amigo português, Gonçalves Braga, participaram da sociedade literária, assim como Justiniano José da Rocha, Gonçalves de Magalhães, Teixeira e Sousa, Laurindo Rabelo, Maciel Monteiro (futuro barão de Itamaracá), Eusébio de Queirós José Maria da Silva Paranhos (futuro visconde do Rio Branco) (MAGALHÃES JÚNIOR, 2008, p. 67), só para citar alguns.

Ao longo de quinze anos, o periódico de Paula Brito recebeu três nomes: A Marmota na Corte (1849-1852), Marmota Fluminense (1852-1857) e A Marmota (1857-1861 e 1864). Simionato, que estudou o jornal em suas três fases, explicou o significado do título, afirmando que o vocábulo "marmota" designa um roedor quadrúpede, espantalho ou fantasma, "e como possuía feições de publicação um tanto primitiva, pode-se pensar que seu nome sugeriria algo desajeitado, assombroso, semelhante a um espantalho" (SIMIONATO, 2009, p. 19). Logo, o título estava de acordo com o propósito do jornal de moralizar através do riso. Além disso, "marmota" também era um tipo de brinquedo ótico - cosmorama ou lanterna mágica - que funcionava como uma caixa que em seu interior possuía espelhos, os quais distorciam as imagens. Assim, o periódico também se orientava por distorcer os fatos e fazer brincadeiras, motes e poemas sobre as coisas sérias.

O jornal era denominado como de pequena imprensa porque se destinava mais aos assuntos literários, e tinha como público os estudantes, caixeiros e as moças. Nele, foram publicadas traduções das Fábulas de Esopo e matérias civilizatórias oriundas de manuais de etiqueta e comportamento europeus, porque seu principal objetivo era formar cultural e moralmente o leitor. A linha editorial da Marmota na Corte pretendia educar a família brasileira de maneira divertida, com poemas e textos diversos. O público feminino estava em maior número e, por isso, comumente apareciam comentários sobre como se comportar nos eventos sociais (teatros, bailes, livrarias, entre outros). Simionato observou, por exemplo, que Próspero Diniz, redator de A Marmota na Corte, assim escreveu para aconselhar as jovens:

[...] entre as atitudes que devem ser evitadas: excesso de risadas e de conversas, trejeitos e 'macaquices' para tentar agradar forçosamente seu interlocutor, passar muito tempo nas janelas, falta de cuidado com o vestuário e com o corpo, dançar demais em bailes [...]. (SIMIONATO, 2009, p. 44)

De todo modo, o periódico de Paula Brito foi a porta de entrada de Machado de Assis para a divulgação de seus textos. Em suas páginas, 
figuraram cinquenta e seis textos machadianos, porém, interessa-nos tratar apenas da Marmota Fluminense, já que o poema "O gênio adormecido" aí apareceu em 1855. Nessa segunda fase, o jornal era composto por três colunas, e não duas, como em A Marmota na Corte. Paula Brito continuou responsável pela direção do jornal e tornou-se seu principal redator, dedicando-se menos a informar notícias da cidade, em benefício da publicação de poemas e de textos de prosa. Bissemanal, aparecia às terças e sextas-feiras com quatro páginas. A primeira trazia em seu cabeçalho o número da edição, o dia da semana e a data. Logo abaixo, o nome do jornal - Marmota Fluminense - e o subtítulo - Jornal de Modas e Variedades - além de informações da tipografia e o preço do exemplar.

Sua primeira coluna sempre era iniciada com a seção "A Marmota", que reproduzia os informes da redação, como a alteração de elementos do jornal, a divulgação de promoções da tipografia, o aparecimento de novas obras literárias e algumas notícias da cidade. Era a parte que se dedicava ao diálogo direto com o leitor. Outra seção, intitulada "Folhetim", funcionava como um espaço para a publicação de textos literários em partes, o que permitia que os escritores soubessem se seus textos seriam bem-aceitos pelo público, se publicados em livro. Nesse sentido, Simionato observou sobre a primeira página do periódico:

Sobre a disposição física dos textos, na página de abertura, havia a já mencionada coluna "A Marmota", com seu conteúdo variado. Além dela, eram divulgados nesse espaço esclarecimentos aos acionistas da Empresa Dous de Dezembro, algumas transcrições de correspondências destinadas a Paula Brito, notícias sobre a família real, comentários acerca de alguma data comemorativa nacional, novidades na corte, artigos sobre moda, textos religiosos e literários e até notícias de falecimento. (SIMIONATO, 2009, p. 23)

A segunda página normalmente funcionava como a primeira, pois trazia a continuação de textos iniciados na página anterior. Já a terceira e quarta páginas continham traduções, motes e glosas e a divulgação de poemas ou, às vezes, traziam artigos sobre um tema qualquer, como as doenças que assolavam a cidade. A última página era a mais dedicada ao entretenimento, com suas charadas, logogrifos, epigramas, anedotas, e contava com anúncios comerciais e de Paula Brito, que divulgava a presença em sua loja de obras editadas, além de outros produtos por ele vendidos, como chás, charutos, cartões e álbuns. 
Na Marmota Fluminense, foram publicados textos literários de escritores conhecidos, tais como Alphonse de Lamartine, Victor Hugo, Joaquim Manuel de Macedo, Santa Rita Durão, Junqueira Freire e do próprio editor Paula Brito.

\section{O poema}

"O gênio adormecido" ${ }^{3}$ foi composto e publicado na Marmota Fluminense em outubro de 1855, um ano após a estreia de Machado de Assis na imprensa. Nele, o jovem poeta pretendeu glorificar a epopeia $A$ Independência do Brasil, de Teixeira e Sousa, cuja primeira parte saiu em 1847 e a segunda no início de 1855 pela tipografia de Paula Brito. Nos versos de Machado, no entanto, predominou o elogio ao autor da epopeia, como observou Massa:

Em "O gênio adormecido", Machado de Assis manipulou mais o incenso do que a análise. Como era incapaz de escrever uma epopeia, admirava a obra do épico brasileiro e anunciou a próxima aparição da continuação e do fim desta série interminável. Teixeira e Sousa era para ele o "gênio americano". (MASSA, 2008, p. 142) ${ }^{4}$

O poeta homenageado, Antônio Gonçalves Teixeira e Sousa, nasceu em Cabo Frio em 1812 e faleceu no Rio em 1861. "Filho de um vendeiro português e de uma mestiça, exerceu sempre ofícios modestos, começando como carpinteiro, e chegando a duras penas a mestre-escola e a escrivão" (BOSI, 2006, p. 106). Segundo Hebe Cristina da Silva, ele atuou muito na imprensa, publicando textos literários de diversos gêneros, principalmente romances, uma vez que "as obras em prosa parecem ter sido as produções de autoria preferidas pelo público, pois todos os seus romances obtiveram ao menos uma edição em volume e uma em folhetim no século XIX". (SILVA, 2018, p. 105)

\footnotetext{
3 Algumas observações sobre esse poema encontram-se desenvolvidas, de forma embrionária, em RODRIGUES, 2019.

${ }^{4} \mathrm{Na}$ Marmota Fluminense, há uma nota que contraria a observação de Massa de que Machado anunciou a aparição da segunda e última parte do poema épico de Teixeira e Sousa, pois "O gênio adormecido" foi composto em outubro de 1855 e o texto da nota, de fevereiro, diz que a segunda parte de $A$ Independência do Brasil poderia ser retirada por aqueles que haviam pago pelo livro a partir de março do mesmo ano. (Marmota Fluminense, Rio de Janeiro, n. 555, 25 fev. 1855, p. 4) Isso também pode ser confirmado na parte "Notícias Diversas" do Tomo III de O Guanabara, publicado em março de 1855: "Está terminada a impressão do segundo volume do poema da - $[A]$ Independência do Brasil - composto pelo nosso particular amigo o sr. Antônio Gonçalves Teixeira e Sousa. É uma epopeia, cujo assunto inteiramente nacional deve interessar a todos os brasileiros, a quem recomendamos a leitura. O autor não é um homem desconhecido; é um poeta de grande talento [...]." (O Guanabara: Revista mensal, artística, científica e literária, Rio de Janeiro, n. 1, Tomo III, mar. 1855, p. 23-24).
} 
Além disso, a pesquisadora notou que os textos críticos da época apontavam o prosador como figura relevante para a formação da literatura brasileira. Nas suas palavras: "[...] seus contemporâneos consideravam-no um autor de importância crucial quando se tratava do estudo do romance brasileiro e, apesar de apontarem alguns problemas em suas narrativas, reconheciam a sua importância para a literatura nacional" (SILVA, 2018, p. 105). No entanto, ao longo do século XIX, suas obras passaram a ser vistas como inferiores. Alfredo Bosi, por exemplo, chamou o escritor de primo pobre do grupo fluminense, e assim como Massa, julgou a obra $A$ Independência do Brasil como "infeliz poemeto épico". (BOSI, 2006, p. 106)

O nome de Teixeira e Sousa, segundo Magalhães Júnior (2008, p. 66), aparece entre os homens de letras que participavam da Sociedade Petalógica e publicavam no jornal de Paula Brito. Aliás, ele era amigo de infância do editor da Marmota Fluminense, tendo sido seu sócio. ${ }^{5}$ Nesse sentido, o poema machadiano parece até mesmo ter sido encomenda do editor da revista, que tinha o objetivo de fazer circular o nome de Teixeira e Sousa e de sua obra épica.

Veja-se o poema de Machado de Assis:

\section{"O gênio adormecido"}

O. D. e C. ${ }^{6}$ Ao Ilm. ${ }^{\circ}$ sr. Antônio Gonçalves Teixeira e Sousa

Do Grego Vate expande-se a harmonia

Em teus sonoros carmes! Na harpa d'ouro

Do sacro Apolo, Trovador, dedilhas

Doces cantos que o espírito arrebata

Ao recinto celeste!

Em cít'ra de marfim, com fios d'ouro

Cantaste infante, para que mais tarde

A fama ativa as tubas embocando

Com voz imensa proclamasse aos mundos

Um Gênio Americano!

E tu dormes, Poeta?! Da palmeira

\footnotetext{
${ }^{5}$ Sobre isso, Gondim assim comentou: "Joaquim Norberto nos dá maiores esclarecimentos sobre a tipografia da rua dos Ourives, n. 21, que segundo sua informação era, também loja de objetos de escritório, montada em sociedade com Teixeira e Sousa, o grande e inseparável amigo de Paula Brito. [...]." (GONDIM, 1965, p. 39)

${ }^{6}$ Ofereço, dedico e consagro.
} 
No verde tronco penduraste a lira

Após nela entoar linda epopeia, Que mal condão funesto à nossa pátria Faz soporoso o Vate!

Vate! Vate! [...] Que morre harmonioso! Semelha um som ao respirar das brisas Nas doces cordas do alaúde d'ouro Pendurado no ramo da palmeira, Que sombreia o regato!

Desperta, ó Vate, e libertando o estro Desprende a voz, e os cânticos divinos; Deixa entornar-se em teus ungidos lábios Como a ribeira deslizando o corpo Cercado de boninas.

Sim, ó Vate, o teu canto é tão sonoro Como os sons da Seráfica harmonia Dos sonorosos cantos sublimados Do doce Lamartine - o Bardo excelso, Da França o belo Gênio!

Toma a lira de novo, e um canto vibra, E depois ouvirás a nossa terra Orgulhosa dizer: - Grécia, emudece, Dos Vates berço, abrilhantado surge O Gênio adormecido!

Rio. - Outubro de 1855.

J.M.M. d'Assis. (ASSIS, 1855f, p. 3-4)

Nesse poema, formado por sete estrofes de versos decassílabos e hexassílabos, o eu lírico se refere a Teixeira e Sousa como "Trovador", "Gênio Americano", "Poeta" e "Vate", colaborando para a construção da imagem do autor como ser divino e habilidoso com a música e a poesia.

Logo na primeira estrofe, é dito que o "Grego Vate", ou seja, o autor das principais epopeias da Grécia Antiga, Homero, proporcionou harmonia aos cantos do brasileiro. Esse seria o maior elogio que alguém poderia fazer ao compositor de uma epopeia, e o eu lírico vai além, ao concluir na última estrofe: "E depois ouvirás a nossa terra/ Orgulhosa dizer: - Grécia, emudece,/ 
Dos Vates berço, abrilhantado surge/ O Gênio adormecido", desse modo, o autor de $A$ Independência do Brasil seria equiparado ao autor da Ilíada e Odisseia.

Teixeira e Sousa foi exaltado ao nível divino, pois ele, figurativamente, dedilha a "harpa d'ouro" do deus mitológico Apolo, visto como deus da música, representado no cume do monte Parnaso. Dessa maneira, nota-se que o eu lírico considera seu elogiado como um poeta profeta, porque este último desprende "cantos divinos" e é chamado de "vate" e "gênio".

O incenso queimado ao épico brasileiro é grande, pois, além disso, os cantos de Teixeira e Sousa são vistos pelo eu lírico, na sexta estrofe do poema (onde ocorre aliteração pelo emprego do fonema /s/), como tão sonoros quanto os cantos sublimados do poeta romântico Alphonse de Lamartine.

Sim, ó Vate, o teu canto é tão sonoro

Como os sons da Seráfica harmonia

Dos sonorosos cantos sublimados

Do doce Lamartine - o Bardo excelso,

Da França o belo Gênio! (ASSIS, 1855g, p. 3-4)

Trata-se, então, de um poema de tom elevado, construído com inversões sintáticas; paralelismos, como "Do Grego Vate/ Do sacro Apolo/ Da palmeira" e "Desperta/ Desprende/ Deixa"; e aliteração, em benefício de sua musicalidade. Aliás, a música adquire grande importância em "O gênio adormecido", pois, como anteriormente observado, o eu lírico pretendeu associar Teixeira e Sousa a uma figura de autor que domina essa arte. O "gênio" do poema dedilha a harpa de um deus; ainda menino, cantou em "cít'ra de marfim"; pendurou sua lira na palmeira e é convidado a imitar "um som ao respirar das brisas/ Nas doces cordas do alaúde d'ouro". Além do mais, aparece outro instrumento musical no poema: "as tubas", que são "embocadas" pela fama [do épico brasileiro], a qual proclama aos mundos "Um Gênio Americano".

É somente na terceira estrofe que o eu lírico conta que Teixeira e Sousa realizou uma composição poética. Segundo ele, o poeta entoou linda epopeia e a pendurou no verde tronco da palmeira, sendo esse um fato provavelmente ocasionado por um poder sobrenatural que conduz o vate à sonolência. $\mathrm{E}$ isso inspira tristeza à pátria, como se pode ver nos versos: "Que mal condão funesto à nossa pátria/ Faz soporoso o Vate!". Sobre a presença da "palmeira" compondo a imagem do país, essa árvore se tornou símbolo da terra e das origens do povo brasileiro, após a publicação do poema "Canção do exílio" 
(1846) de Gonçalves Dias, sendo sempre relacionada aos temas nacionalistas. Assim, ela aparece no poema dedicado a Teixeira e Sousa, o "Gênio americano", indicando que ele é um excelente épico, cantor do que há de mais nacional.

A paisagem, suscitada no poema, constrói uma imagem romântica de Brasil. Este é um país em que se veem palmeiras; regatos, ou seja, riachos ou correntes d'água; ribeiras, isto é, margens de pequenos rios; e boninas, espécie de erva europeia, bela-margarida. Logo, têm-se aí uma natureza mais amena, sem selvas, e plantas originárias de suas terras.

É possível que, em "O gênio adormecido", Machado de Assis, juntamente de seu editor, tenham utilizado o poema com fins publicitários. A figura do prosador Teixeira e Sousa parecia intacta devido ao seu pioneirismo nos folhetins e edição de romances; porém, a consagração do poeta como épico fazia-se necessária, já que $A$ Independência do Brasil não havia feito sucesso entre o público leitor. Conforme Massa:

O elogio de Machado de Assis não teve o efeito esperado. Em fevereiro de 1855, quando os últimos cantos de $[A]$ Independência do Brasil saíam dos prelos de Paula Brito, foram acolhidos com total indiferença. A obra daquele que Machado de Assis, na sua primeira apreciação crítica igualava a Homero, cairá no mesmo esquecimento morno ligado à epopeia. (MASSA, 2009, p. 142) ${ }^{7}$

Não só Machado de Assis colaborou para a legitimação do autor Teixeira e Sousa, utilizando uma forma literária altamente valorizada e termos relacionados ao âmbito religioso para consagrá-lo. Seu amigo português, Gonçalves Braga, compôs o poema "Ode ao senhor Antônio Gonçalves Teixeira e Sousa (Poeta brasileiro - Em resposta)" em julho de 1855. A composição poética possui epígrafe com versos de Teixeira e Sousa ("é morto o vate.../ Toma, pois, seu lugar...") e tem algumas estrofes aqui reproduzidas:

\footnotetext{
Não morreste, Poeta! O sacro fogo,

Esse fogo que Deus outorga a Apolo,

E que Apolo depois transmite ao Vate,

Inda arde no teu peito.
}

Não morreste, Poeta! A tua lira

\footnotetext{
${ }^{7}$ Vide nota 5 , em que se pode ver que o poema machadiano é posterior à publicação da segunda parte de A Independência do Brasil.
} 
Inda conserva as sonorosas cordas

Com que outrora cantaste a - INDEPENDÊNCIA -

Do teu Brasílio Império.

$[\ldots]$

Então tomando a lira em que cantaste

O famoso - NOIVADO DE MIRYBA ${ }^{8}$, -

Cantarás, meu Teixeira, em harpas d'anjos

Divinas Epopeias!

Por fim, quando este mundo abandonares,

Elevado da essência augusta, e santa,

Deixarás de ser homem, serás Deus

No cume do Parnaso! (BRAGA, 1856, p. 194-195)

A semelhança entre os poemas de Machado de Assis e Braga é evidente, tanto na forma quanto em relação ao conteúdo. Primeiro, observa-se que os versos são brancos e há decassílabos e hexassílabos dispostos como no poema "O gênio adormecido", com exceção de que neste se encontra um verso de dez sílabas a mais em cada estrofe. E segundo, o elogio é o mesmo: Braga afirma que o poeta não morreu, e Machado diz que ele dorme ainda e deve despertar; o deus Apolo também aparece dando ao poeta elogiado o fogo sagrado, ou seja, a inspiração; há a menção à obra épica $A$ Independência do Brasil, considerada pelo português como sonora; e, por último, nota-se a atitude imperativa do eu lírico que, indiretamente, solicita que o épico tome a lira e cante divinas epopeias. Machado foi mais direto:
Desperta, ó Vate, e libertando o estro
Desprende a voz, e os cânticos divinos;
Deixa entornar-se em teus ungidos lábios
Como a ribeira deslizando o corpo
Cercado de boninas. (ASSIS, 1855g, p. 3-4)

Além dos poemas de Machado e Braga, encontramos um outro dedicado a Teixeira e Sousa, presente na Marmota Fluminense. É um soneto que traz novamente a comparação entre o autor d'A Independência do Brasil e o deus

\footnotetext{
${ }^{8}$ Trata-se do poema em cinco cantos "Os três dias de um noivado" de Teixeira e Sousa, publicado pela tipografia de Paula Brito em 1844, e que teve alguns versos reproduzidos em edições da Marmota Fluminense de 1857.
} 
Apolo, contribuindo para a constituição de uma figura divina e talentosa com a música e a poesia. Vejam-se as duas primeiras estrofes:

\section{Soneto}

O. D. C. ao Ilm. ${ }^{\circ}$ sr. Antônio Gonçalves Teixeira e Sousa

Qual Apolo expandindo flava cor,

No horizonte, de seu plaustro dourado;

Qual Lucina com seu manto prateado,

Difunde em nossas almas horas d'amor;

Assim tu, oh gênio arrebatador!

M'enlevas quando tuas obras leio;

Deixando-me com o peito sempre cheio

De suavidade e d'uma amena dor! (CAMPOS FLUMINENSE, 1858, p. 4.)

Os colaboradores do periódico, no caso Machado de Assis, Gonçalves Braga e Campos Fluminense, podem haver sido tomados naturalmente por uma intenção de homenagear Teixeira e Sousa, tendo lido talvez os poemas um do outro, pois estes apresentam formas e temas semelhantes. Da mesma forma, é possível que Paula Brito tenha recomendado a construção desses textos (nas reuniões da Sociedade Petalógica, por exemplo) e, assim, a imagem do autor de $A$ Independência do Brasil foi aos poucos sendo construída na Marmota Fluminense de maneira coletiva e serviu para fins publicitários.

Sobre a dinâmica de colaboração em jornais do século XIX e a relação entre autores e editores nesse suporte, Marie-Ėve Thérenty comentou:

A nova mídia [o jornal do século XIX], igualmente, impõe um novo ritmo de escrita ao escritor jornalista, além de tornar coletiva a redação de um número diário, semanal ou mensal em torno de uma figura central (editor, diretor, proprietário do jornal), o que resulta em uma natureza verdadeiramente polifônica da escrita [...]. (THÉRENTY apud GRANJA, 2018, p. 26).

Nesse sentido, os três poemas aqui citados, que apresentam semelhanças entre si, assim dialogam porque seus autores participavam da mesma rede de relações literárias e eram guiados por uma figura central, Paula Brito, que 
escolhia os textos e fazia sugestões com o fim de alinhá-los ao propósito do jornal e à temática do número semanal.

\section{Considerações finais}

O conhecimento da natureza do periódico Marmota Fluminense, que serviu de suporte para a publicação de "O gênio adormecido" de Machado de Assis, e da rede de relações que sustentou sua existência no Rio de Janeiro de meados do século XIX, especialmente sobre seu editor, Francisco de Paula Brito, permitiu-nos uma melhor aproximação e análise do texto literário machadiano.

O jovem poeta Machado de Assis, assim como seus pares, colaboradores do periódico, provavelmente atuava de acordo com a "mente do editor", 9 compondo versos que, além de consagrar um mestre ou amigo, colocavam novamente seu nome em circulação. Em "O gênio adormecido", Teixeira e Sousa terminava legitimado como poeta épico em contato com o sagrado e detentor de habilidades musicais, sobretudo, poéticas. Um gênio americano.

\section{Referências}

ASSIS, Machado de. Soneto à Ilma. sra. D.P.J.A. Periódico dos Pobres, Rio de Janeiro, n. 103, out. 1854. Disponível em: <http://memoria.bn.br/DocReader/docreader.aspx?bib=709697\&pasta $=$ ano $\% 20185 \&$ pesq=>. Acesso em: 12 fev. 2020.

Ela. Marmota Fluminense, Rio de Janeiro, n. 539, jan. 1855a. Disponível em:

$<$ http://memoria.bn.br/DocReader/docreader.aspx?bib=706914\&pasta $=$ ano $\% 20185 \&$ pesq=>. Acesso em: 12 fev. 2020 .

A palmeira. Marmota Fluminense, Rio de Janeiro, n. 540, jan. 1855 b. Disponível

em: $<$ http://memoria.bn.br/DocReader/docreader.aspx?bib=706914\&pasta $=$ ano $\% 20185 \&$ pesq=>. Acesso em: 12 fev. 2020 .

Saudades. Marmota Fluminense, Rio de Janeiro, n. 578, mai. 1855c. Disponível

em:

\footnotetext{
${ }^{9}$ Expressão retomada de Chartier: "[...] a mão do autor, no momento em que um escritor pega de sua pena, existirá conjuntamente com a mente do editor". (CHARTIER apud GRANJA, 2018, p. 22)
} 
<http://memoria.bn.br/DocReader/docreader.aspx?bib=706914\&pasta =ano $\% 20185 \&$ pesq=>. Acesso em: 12 fev. 2020.

A saudade. Marmota Fluminense, Rio de Janeiro, n. 632, out. 1855d. Disponível

em: <http://memoria.bn.br/DocReader/docreader.aspx?bib=706914\&pasta =ano\%20185\&pesq=>. Acesso em: 12 fev. 2020.

. No álbum do sr. F.G. Braga. Marmota Fluminense, Rio de Janeiro, n. 634, out. 1855e. Disponível em: <http://memoria.bn.br/DocReader/docreader.aspx?bib=706914\&pasta $=$ ano $\% 20185 \&$ pesq=>. Acesso em: 12 fev. 2020.

O gênio adormecido. Marmota Fluminense, Rio de Janeiro, n. 642, 28 out. 1855f. Disponível em: <http://memoria.bn.br/DocReader/docreader.aspx?bib=706914\&pasta =ano $\% 20185 \&$ pesq=>. Acesso em: 12 fev. 2020.

. Soneto a S.M. o imperador, o senhor d. Pedro II. Marmota Fluminense, Rio de Janeiro, n. 654, dez. 1855g. Disponível em: $<$ http://memoria.bn.br/DocReader/docreader.aspx?bib=706914\&pasta =ano\%20185\&pesq=>. Acesso em: 12 fev. 2020.

Esperança. Correio Mercantil, e Instructivo, Político, Universal, Rio de Janeiro, n. 290, out. 1858. Disponível em: <http://memoria.bn.br/DocReader/docreader.aspx?bib=217280\&pasta =ano\%20185\&pesq=>. Acesso em: 12 fev. 2020.

. Comentários da Semana. Diário do Rio de Janeiro, Rio de Janeiro, n. 351, 24 dez. 1861, p. 1. Disponível em: <http://memoria.bn.br/DocReader/docreader.aspx?bib=094170_02\&p asta $=$ ano\%20186\&pesq=>. Acesso em: 12 fev. 2020.

BOSI, Alfredo. História concisa da Literatura Brasileira. 43. ed. São Paulo: Cultrix, 2006.

BRAGA, Francisco Gonçalves. Tentativas poéticas. Rio de Janeiro: Tipografia de Nicolau Lobo Vianna \& Filhos, 1856.

CAMpos Fluminense, A. da S. Soneto O. D. C. ao Ilm. ${ }^{\circ}$ sr. Antônio Gonçalves Teixeira e Sousa. Marmota Fluminense, Rio de Janeiro, n. 914, $5 \quad$ jan. $1858 . \quad$ Disponível em: <http://memoria.bn.br/DocReader/docreader.aspx?bib=706914\&pasta $=$ ano\%20185\&pesq=>. Acesso em: 12 fev. 2020.

CHARTIER, Roger. O que é um autor? Revisão de uma genealogia. Trad. Luzmara Cursino; Carlos Eduardo de Oliveira Bezerra. São Carlos: EdUFSCar, 2012. 
GONDIM, Eunice Riberio. Vida e obra de Paula Brito. Rio de Janeiro: Livraria Brasiliana Editora, 1965.

GRANJA, Lúcia. Machado de Assis - antes do livro, o jornal: suporte, mídia e ficção. São Paulo: Editora Unesp Digital, 2018.

GRIMAL, Pierre. Dicionário da Mitologia Grega e Romana. Trad. Victor Jabouille. 5. ed. Rio de Janeiro: Bertrand Brasil, 2005.

MAGALHÃES JÚNIOR, Raimundo. Machado de Assis: vida e obra (aprendizado). 2. ed. Rio de Janeiro; São Paulo: Record, 2008, v. 1.

MASSA, Jean-Michel. A juventude de Machado de Assis: ensaio de biografia intelectual (1839-1870). Trad. Marco Aurélio de Moura Matos. 2. ed. São Paulo: Editora Unesp, 2009.

RODRIGUES, Cristiane Nascimento. Machado de Assis: da poesia ao ensaio de crítica literária. In: SANDANELLO, Franco Baptista; MARQUES, Wilton José (Orgs.). Leituras oitocentistas São Carlos: EdUFSCar, 2019. p.65-83.

SILVA, Hebe Cristina da. A recepção de Teixeira e Sousa - o escritor renomado e o autor secundário. Revista de Estudos Literários da UEMS, Mato Grosso do Sul, v. 2, n. 7, 2013, p. 104-118. Disponível em: <http://periodicosonline.uems.br/>. Acesso em: 20 out. 2018.

SIMIONATO, Juliana Siani. A Marmota e seu perfil editorial: contribuição para edição e estudo dos textos machadianos publicados nesse periódico (1855-1861). 2009. 301 f. Dissertação (Mestrado em Teoria e Pesquisa em Comunicação) - Escola de Comunicação e Artes, Universidade de São Paulo, São Paulo, 2009.

CRISTIANE NASCIMENTO RODRIGUES é doutoranda em Estudos de Literatura na Universidade Federal de São Carlos e integra o grupo Núcleo de Estudos Oitocentistas NEO/UFSCar. Recentemente publicou o capítulo "Machado de Assis: da poesia ao ensaio de crítica literária" em Leituras Oitocentistas, organizado por Sandanello \& Marques (EdUFSCar, 2019), co-organizou o livro Autres voix. Textes en philosophie de l'existence (Éditions DL\&DR, 2019) e é autora de "Gonçalves Braga : o jovem mestre português de Machado de Assis" (MAEL, 2018). (1): https://orcid.org/0000-0001-5176-4340

E-mail: cristianerodrigues@estudante.ufscar.br

Recebido em: 12.01.2020

Aprovado em: 15.02.2020 